Association for Information Systems AIS Electronic Library (AISeL)

Wirtschaftsinformatik Proceedings 2005

Wirtschaftsinformatik

February 2005

\title{
A Comparison of Paradigmatic Views in Knowledge Management: An Empirical Case Study on Shortcomings in KM
}

Bertolt Meyer

Humboldt-University Berlin

Wolfgang Scholl

Humboldt-University Berlin

Follow this and additional works at: http://aisel.aisnet.org/wi2005

\section{Recommended Citation}

Meyer, Bertolt and Scholl, Wolfgang, "A Comparison of Paradigmatic Views in Knowledge Management: An Empirical Case Study on Shortcomings in KM" (2005). Wirtschaftsinformatik Proceedings 2005. 52.

http://aisel.aisnet.org/wi2005/52

This material is brought to you by the Wirtschaftsinformatik at AIS Electronic Library (AISeL). It has been accepted for inclusion in Wirtschaftsinformatik Proceedings 2005 by an authorized administrator of AIS Electronic Library (AISeL). For more information, please contact elibrary@aisnet.org. 
In: Ferstl, Otto K, u.a. (Hg) 2005. Wirtschaftsinformatik 2005: eEconomy, eGovernment, eSociety; 7. Internationale Tagung Wirtschaftsinformatik 2005. Heidelberg: Physica-Verlag

ISBN: 3-7908-1574-8

(C) Physica-Verlag Heidelberg 2005 


\title{
A Comparison of Paradigmatic Views in Knowledge Management: An Empirical Case Study on Shortcomings in KM
}

\author{
Bertolt Meyer, Wolfgang Scholl \\ Humboldt-University Berlin
}

\begin{abstract}
Four Paradigmatic views that explain shortcomings of knowledge management systems (KMS) in literature are identified: Organizazional barriers, codification vs. personalization, importance of a clear working definition of knowledge and impossibility to manage knowledge or certain forms of it. Their validity is analyzed by comparing them to a case study in which shortcomings of two KMS in an international company were analyzed. Factor analyses and linear structural models identified three factors that account for the acceptance of one of the systems: system quality, personal attitude towards KM and organizational culture / barriers. The linear structural model partly supports the first three paradigmatic views. Further efforts for incorporating different concepts in KM into a single conceptual framework appear necessary and possible.
\end{abstract}

Keywords: Knowledge management, knowledge management systems, barriers

\section{Introduction}

The significance of knowledge as a vital resource for the world's economies has been underlined in science and politics. Examples include Stehr's introduction of the term "knowledge society" [Steh94] and the ambitious aim of the European Union to become one of the world's "leading knowledge-based economies" [Euro00, p. 1].

Especially in times of highly competitive and rapidly changing environments, knowledge forms the basis for innovation and economic success [DaPr98; Druc93; NoTa95; Scho04; ScGe03]. Knowledge management (KM) is the strategy for the management of this vital resource, and has evolved from a hyped buzzword to an accepted strategy, as a study on future management strategies indicates [Noac03]. However, the early enthusiasm has faded since concrete applications of KM concepts in business, especially in form of IT-based knowledge-management-systems (KMS), fell short of expectations [Malh04; Schn01; ScGe03; Schü03; Snow02]. This paper seeks to give an overview of different views that intend to explain the 
shortcomings of systems in use, evaluate them empirically, and derive some ideas for an integrative framework.

The empirical research pertains to two knowledge management systems (referred to as systems A and B) within a large multinational service company with more than 100,000 employees which were evaluated in an empirical field study. The situation within this organization appeared as follows: System A was in operation since 1999 and was designed as a global knowledge management system. It took more than two years to develop it; the development was carried out by a central team that included many external consultants but had little contact with the employees intended to use the system. Planned as a global platform for collaboration and communication, its core is a database system to which employees supply documents which are categorized on three dimensions mapping the structure of the organization. In this way, the database structure is intended to allow the employees to specify the context in which they work and to easily retrieve all documents relevant to them. The system also contained communication tools and a facility for searching CVs. Three years after introduction, the system was hardly used, internal strategy papers referred to "not only positive experiences", and employees nicknamed the system "nirvana".

System B was designed by employees of a specific department in 2000 in order to elude the shortcomings of system A, as the initiator of the system put it. It is a intranet website with access to different sets of documents, guidelines and archives. The content is structured with a simple menu-based navigation; communication and collaboration tools are not included. It was used more frequently than the system A but it had also some shortcomings, e.g. no search function. In order to explore the shortcomings of both systems, the literature was scanned for other experiences and explanations of KMS shortcomings, which are grouped in section 2 . The situation in the cooperating organization was then surveyed with interviews and questionnaires (section 3). Factor analysis of the questionnaire data led to four factors that condition the acceptance of system B. The factors were then inserted into a structural model in order to quantify their influence on the systems' acceptance (section 4). In section 5, the results are compared to the paradigmatic views identified in section 2 and are integrated into a conceptual framework for barriers in knowledge management systems.

\section{Paradigmatic Views on Shortcomings in KM}

Before analyzing knowledge management strategies and systems, it is vital to provide working definitions for the terms "knowledge" and "knowledge management". Since no definition can claim prime usefulness, a working definition for 
knowledge is chosen that is broad enough to incorporate all different forms of knowledge, including both individual and organizational knowledge ${ }^{1}$ :

"Knowledge is the entirety of all products of learning, in which data is perceived as information and is stored as structural connectivity patterns" [Güld99, p. 161, own translation].

Knowledge management is then defined as the coordinated, structured and supported use, creation and sharing of knowledge within an organization. [ReMa00, p. 9].

Knowledge processes in organizations are usually supported by IT-based knowledge management systems, a heterogeneous group of systems [GrKa02], that often focus on the externalization and storage of explicit ${ }^{2}$ knowledge [Schü03].

However, these systems frequently failed or fell short of expectations [FaPr98; Malh04; Schn01; Snow02]. The hypothetical reasons proposed in the literature can be categorized into four groups:

1. Organizational barriers, both structural and cultural, that exist on both individual and collective levels. These include a lack of time or insufficient motivation for KM, lead to stock-piling of knowledge and exertion of power [Ambr00; Nort99]. Furthermore, insufficient budgets and the small scale of some projects belong into the category of organizational barriers [Ambr00], as well as limiting organizational paradigms and traditions [Schü96; VKro98]

2. Hansen, Nohira and Tierney [Han $\left.{ }^{+} 99\right]$ as well as Sveiby [Svei01] claim that failure of IT-based KM-systems is due to the fact that organizations employ either codification or personalization strategies in KM, where they ideally should be doing both. Codification refers to a database-orientated strategy as outlined above, whereas personalization refers to the linkage of people in real face-toface contact.

3. The third group is dominated by criticism of a missing or ill-conceived working definition of knowledge in the design of IT-based KM-systems [FaPr98; Malh04; Schn01; Snow02]. The (implicit) assumption that knowledge is a storable "thing" or "object" when designing a KM-system leads to an emphasis on storage and a neglect of knowledge flows. An ill-conceived or missing definition of knowledge also leads to the assumption that humans gather and process knowledge in a similar way as computers process information [FaPr98]. The lack of a good working definition of knowledge also leads to a neglect of socio-technical system design [Schn01], and to an ignorance of the importance of shared context [NoKo98; Snow02].

1 Extended discussions of the term "knowledge" can be found in Amelingmeyer [Ame102], Güldenberg [Güld99], and Davenport and Prusak [DaPr98].

2 Compare [NoTa95] for the concept of explicit knowledge. 
4. For the most radical group, the view is that knowledge in general or some forms of it are entirely unmanageable. Schreyögg and Geiger [ScGe03] state that tacit knowledge, as Nonaka and Takeuchi [NoTa95] define it, is unmanageable, because an externalization of tacit knowledge is impossible since embodied knowledge, as Polanyi saw it, cannot be made explicit (otherwise, it would not be tacit knowledge) [Pola66]. Stacy [Stac01] takes up the most extreme position by stating that knowledge is entirely unmanageable.

\section{Method}

The two knowledge management systems A and B were evaluated in an empirical field study. In order to meet Snowden's criticism that empirical research in KM tends to prove every theory that is being tested [Snow02], the employed questionnaire was not derived from the above views but was constructed on the basis of prior semi-structured interviews with 34 senior managers. Partly based on the critical incident technique [Flan54; Foun99], these interviews were used to develop hypotheses and appropriate questionnaire items on possible shortcomings of these systems, independently from the above views. After having completed the survey, the sample was split in two sub-samples. Basic variables were identified by the use of factor analysis on the first sub-sample. These factors were then incorporated into a linear structural model, predicting the degree of acceptance of of each KMS; the reaulting models were cross-validated with the second subsample. Finally, the results of the models were compared to the four paradigms, allowing a test of their theses.

\subsection{Interviews}

34 interviews were conducted with members of the senior staff (all participants had managerial responsibility) of one large department with multiple locations in Germany. They were partly based on the critical incident technique [Flan54]. which is well described by Fountain:

"Incidents typically include three features: a description of the situation, an account of the actions or behavior of the key player in the incident, and the outcome or result. Incidents are typically reported as examples of 'effective' or 'ineffective' actions" [Foun99, p. 1].

The senior managers had an average affiliation with the company of 12.25 years, and their assessments of the systems were thought to be crucial. The interviewees were asked about (a) their expectations of system A and whether they were met, (b) misgivings towards the system, (c) their perception of the introduction of system A and (d) the experience of critical incidents in which either system, A or B, 
failed to function in the desired manner. The incident was then further specified. In addition, their current demand for information was surveyed by asking what kind of information they access, most frequently (e). Finally, they were asked whether they agreed with the company's internal strategists that system A had fallen short of expectations (f). If the interviewee agreed, he or she was asked for possible reasons.

The next step was a simple content analysis: keywords were located in answers to questions (a), (d) and (f). Whenever keywords of answers were similar, these answers were grouped into categories which were then labeled. For (a) and (d), the assignment of the different categories to all answers was done by nine independent expert raters with an average inter-rater-correlation $r=.79$ for (a) and $r=.74$ for (d). The analysis of the answers to question (f) did not require outside raters, as no data-reduction was intended on this exploratory level. The analysis of answers for questions (a), (d) and (f) supplied the statements about barriers which were then used to construct the questionnaire.

\subsection{Questionnaire}

The questionnaire consisted of 45 items: Two items asked for the frequency of system usage for system A and system B. These items had frequency scales with seven alternatives (from $1=$ almost every day to $6=$ never and $7=\mathrm{I}$ do not know this system). 28 items were derived from 14 interview statements that referred to the systems (questions (a), (d) and (f)), two were general evaluation items ("all in all, I think that system $\mathrm{A} / \mathrm{B}$ is a good thing."). Two items were specific to system A: The usage of the system manual and the participation in training (both were not available for system B). The next block of eleven items asked for organizational and motivational factors with regard to the use of KMS which had been derived from interview statements as well. All these items were presented as statements with five-level agreement scales $(1=$ strongly agree, $3=$ partly agree, partly disagree, $5=$ strongly disagree).

The questionnaire was completed by 615 of 2500 employees from one specific department in Germany (return ratio of $24.6 \%$ ), The items of each block were displayed at random order and their polarity altered. Personal data such as sex, age, position, department etc could not be gathered due to privacy protection regulations. The sample is assumed to be largely representative on the basis of its large size and the - compared to other surveys - relatively good participation rate.

\subsection{Factor Analysis}

The sample was divided into two sub-samples, using random assignment of cases: sample $1(\mathrm{~N}=307)$ and sample $2(\mathrm{~N}=308)$. Two factor analyses (oblimin rotation due to probable factor intercorrelation) were performed on sample 1: one for sys- 
tem A and one for system B. Factor analysis reduces the complexity of a set of variables or items by identifying groups of items that seem to be influenced by a single underlying variable (factors).

\subsection{Linear Structural Models}

If a factor for system acceptance could be found, it would be desirable to quantify the effect of the other factors on it. Since the factors are latent (not directly observable) variables between which a causal relation is assumed, linear structural modeling is the preferred method [JöSö93; JöSö79]. Linear structural modeling allows the estimation of relationships between latent variables (factors).

The models were developed with the SIMPLIS command language [JöSö93] and LISREL 8.54 [JöSö03]. Due to the fact that ordinal questionnaire data was used, the weighted least-squares algorithm for polychoric correlations was employed, including the asymptotic covariance matrices [JöSö93, 44]. Models were developed exploratively on sample 1 by iteratively considering modification indices supplied by LISREL. The complete model was then tested on sample 2.

\section{Results}

\subsection{Interviews}

$85 \%$ of the interviewees said that they had expectations on the introduction of system A (which was the first system to be introduced). $83 \%$ stated that their expectations towards system A were partly or fully disappointed (question (a)). When questioned on the reasons for their impression of the system's shortcomings, the following were stated (frequency in brackets): inability to locate information (either because it was not in the system or it could not be found) (12), lack of process orientation (2), problems with reference to organizational culture (2), poor or insufficient data (2), superiority of informal information channels (2), technical flaws of the system (1), and a feeling of information overload (1).

The interviewees were also asked whether they had any fears or reservations about the introduction of a knowledge management system; only five (14\%) agreed and only one interviewee stated that his fear actually had come true. When questioned about critical incidents with the system, $80 \%$ of the interviewees were capable of remembering such a situation. Fourteen reported cases occurred with system A, nine with system B, and five with other systems. The case in which information was undiscoverable occurred 21 times, superiority of unofficial channels was stated four times, poor or insufficient quality of search results three times and the 
feeling of information overload twice. When questioned on the kind of information that they access most frequently (e), none of the respondents specified a need for personal experience reports, CVs, best practices, or public discussions.

Answering the last question regarding the fulfillment of the original KM vision of a global company- and world-wide platform for collaboration and communication, $82 \%$ of the interviewees stated that they do not see that this vision had come true. The specified reasons along with their frequencies can be found in table 1 .

\begin{tabular}{llll}
\hline Nr. & Stated reasons & Stated & Stated in \% \\
\hline 1 & global focus unsuitable & 13 & $29 \%$ \\
2 & desired information undiscoverable & 9 & $20 \%$ \\
3 & superiority of informal communication & 4 & $9 \%$ \\
4 & poor data & 3 & $7 \%$ \\
5 & blurred responsibilities and poor organization & 3 & $7 \%$ \\
6 & information overload & 2 & $4 \%$ \\
7 & unsuitable for mobile working & 2 & $4 \%$ \\
8 & no time for knowledge sharing & 2 & $4 \%$ \\
9 & problems with organizational culture & 2 & $4 \%$ \\
10 & excessive expectations about the system & 1 & $2 \%$ \\
11 & poor integration of existing systems & 1 & $2 \%$ \\
12 & no need for knowledge management & 1 & $2 \%$ \\
13 & language difficulties & 1 & $2 \%$ \\
14 & technical flaws & 1 & $2 \%$ \\
\hline & & 45 & $98 \%{ }^{a}$ \\
\hline
\end{tabular}

${ }^{a}$ the difference to $100 \%$ is caused by truncation

Table 1: Stated reasons for the perceived failure of the original KM vision 


\subsection{Questionnaire}

\begin{tabular}{|c|c|}
\hline Label & Items targeting the systems as presented in the questionnaire \\
\hline Information overload & $\begin{array}{l}\text { The system contains too much. I have a feeling of "information } \\
\text { overload". }\end{array}$ \\
\hline Retrievability & When I look for information, I usually find what I am looking for. \\
\hline Keywording / Meta Data & $\begin{array}{l}\text { The information I find in the system has good keywords or meta- } \\
\text { tags. }\end{array}$ \\
\hline Lack of 'glanceability' & The system is easy to glance and assimilate at a grasp. \\
\hline Content meets requirements & $\begin{array}{l}\text { The information I find on the system... } \\
\text {...meets my requirements completely. }\end{array}$ \\
\hline Specificity & ...is specific and concrete enough for my requirements. \\
\hline Up-to-dateness & ...is up-to-date. \\
\hline Availability & The system is available whenever I need it. \\
\hline Load time & The system responds quickly with short loading (?) times. \\
\hline Belief in relevance of system & I credit relevance to the system. \\
\hline Content in required language & The information I get from the system is in the required language. \\
\hline Technical flaws & I encountered technical flaws while using the system. \\
\hline Bad experiences & I had some bad experiences using the system. \\
\hline Process orientation & The system is designed in accordance with business processes. \\
\hline Label & Items targeting organizational culture \& barriers \\
\hline $\begin{array}{l}\text { No time or resources for } \\
\text { knowledge sharing }\end{array}$ & $\begin{array}{l}\text { Unfortunately, my responsibilities do not give me enough time to } \\
\text { care for KM. }\end{array}$ \\
\hline $\begin{array}{l}\text { Superiority of unofficial in- } \\
\text { formation channels }\end{array}$ & $\begin{array}{l}\text { If I want to know something, I pick up the phone instead of search- } \\
\text { ing in system A, B or elsewhere }\end{array}$ \\
\hline Fear of knowledge sharing & $\begin{array}{l}\text { I am afraid of making my material public because I fear to be } \\
\text { judged by colleagues }\end{array}$ \\
\hline 'Knowledge is power' attitude & Sharing knowledge bears the risk of making me less needed. \\
\hline Legal barriers & $\begin{array}{l}\text { In our company, legal barriers prevent the free sharing of knowl- } \\
\text { edge. }\end{array}$ \\
\hline Responsibilities for KM & $\begin{array}{l}\text { In our company, the responsibilities concerning KM are adequately } \\
\text { defined. }\end{array}$ \\
\hline Insufficient rewards for KM & $\begin{array}{l}\text { In our company, one is not rewarded in any way for commitment to } \\
\mathrm{KM} \text {. }\end{array}$ \\
\hline $\begin{array}{l}\text { Feeling of inadequate knowl- } \\
\text { edge about KM }\end{array}$ & $\begin{array}{l}\text { In our company, the actual meaning and definition of } \mathrm{KM} \text { has been } \\
\text { poorly communicated. }\end{array}$ \\
\hline Equating KM with KMS & In my view, KM primarily (has something to do with) is about IT. \\
\hline $\begin{array}{l}\text { Development beyond personal } \\
\text { needs and requirements }\end{array}$ & $\begin{array}{l}\text { There was insufficient analysis of whether I need a KM system, and } \\
\text { what it should look like. }\end{array}$ \\
\hline $\begin{array}{l}\text { Belief in the general relevance } \\
\text { of KM }\end{array}$ & $\begin{array}{l}\text { All in all, I consider } \mathrm{KM} \text { to be an important thing, to which our } \\
\text { company should be committed. }\end{array}$ \\
\hline
\end{tabular}

Table 2: Questionnaire items (derived from interview statements) 
Example statements from the interviews that led to the categories described above were presented as items in the questionnaire (see table 2).

In order to verify the impression that system B is more widely accepted than system $\mathrm{A}$, the means for general evaluative items are compared with T-tests ${ }^{3}$ (see table 3). The impression that system B is more popular and used more frequently than system A is statistically supported. All values differ significantly and to a very large degree (all effect sizes are above .80).

\begin{tabular}{|c|c|c|c|c|c|c|c|}
\hline \multirow[b]{3}{*}{ Item } & \multirow[b]{3}{*}{$n$} & \multicolumn{4}{|c|}{ Evaluated system } & \multirow[b]{3}{*}{$p(t)$} & \multirow[b]{3}{*}{$d^{\mathrm{c}}$} \\
\hline & & \multicolumn{2}{|c|}{ A } & \multicolumn{2}{|c|}{ B } & & \\
\hline & & $M$ & $S D$ & $M$ & $S D$ & & \\
\hline $\begin{array}{l}\text { Frequency } \\
\text { of usage }^{\mathrm{a}}\end{array}$ & 615 & 3.40 & 1.25 & 5.57 & 1.06 & .000 & 1.87 \\
\hline $\begin{array}{l}\text { General } \\
\text { evaluation }\end{array}$ & 443 & 3.44 & 1.06 & 4.49 & .69 & .000 & 1.22 \\
\hline Relevance $^{b}$ & 438 & 3.44 & 1.02 & 4.47 & .70 & .000 & 1.17 \\
\hline
\end{tabular}

Notes. ${ }^{\text {a }}$ inverted frequency scale with seven alternatives from $7=$ almost every day to $2=$ never, $1=$ I do not know this system. ${ }^{b}$ agreement scale with five alternatives from $1=$ strongly disagree to $5=$ strongly agree; for items see table $2 .{ }^{\mathrm{c}}$ Effect size: Cohen's d.

Table 3: Comparison of means between system A and B (t-test with paired samples), evaluating and judging items

The rest of the items with reference to the specific systems (upper section of table 2) differ in similar ways as those in table 3: system $B$ receives better ratings for every single item. T-tests for paired samples are significant on 0.001-level for every item; Cohen's d is larger than .80 for all items except for 'Keywording' (.72) and 'Required Language' (.76). Thus, the simpler, local system B is seen as superior to A in every respect.

\subsection{Factor Analyses}

Factor analyses are intended to identify groups of items that are influenced by a single underlying construct by being highly correlated. If a separate factor of system acceptance can be found, the influence of other factors on that acceptance factor can be analyzed. In the following, two factor analyses are performed: one for system A and one for system B.

3 See [Labo70] for the validity of using ordinal data for t-tests. 


\subsubsection{System A}

The factor analysis for system A included all items with reference to system A as well as the items with reference to organizational aspects. The first factor had a relatively high variance $(25.5 \%)$. The scree test indicated a four-factor solution, which was adopted with an oblique rotation leading to the best available simple structure. The factor correlations were low, the highest being -.11 between factor I and II. The rotated four factor solution accounts for $46.6 \%$ of the overall variance. The pattern matrix is omitted in this conference paper and is available from the authors on request.

Factor I incorporates nine highly loading items ( $>$.7). On the one hand, these consist of seven items with reference to the system quality: 'Specificity', 'Retrievability', 'Glanceability', 'Process orientation', Content meets requirements', 'Keywording' and 'Up-to-dateness'. On the other hand, it includes two overall evaluative items: 'General evaluation' and 'Relevance of system A'. A third item with general relevance, 'Frequency of usage', loads with .52. This factor is thus a mixture of system A's specific features and its general acceptance and use. Taking into account that this factor has high loadings from more than $50 \%$ of items from different domains, one has to arrive at the conclusion that this factor represents the generalized attitude towards system A.

Factor II consists of the items 'Inadequate time and resources for KM', 'Inadequate reward for KM' and 'Development beyond personal requirements'. The weaker loadings of 'Clear responsibilities in KM' (with a negative algebraic sign), 'Legal barriers' and 'Inadequate knowledge about KM' support the label 'Organizational barriers' for this factor.

Factor III incorporates the 'Knowledge is power' and 'Fear of judgment' items. It is thus named 'Personal attitude towards $K M$ ', since these items both refer to a specific (anxious) attitude towards KM .

Factor IV refers to 'Knowledge about system' A. Although it only consists of one item loading > .6 ('Usage of system manual'), the weaker loadings of 'Participation in system training' and 'Technical flaws' support this interpretation.

Since it was not possible to identify a separate factor for the acceptance of system A, the influence of other factors onto the acceptance of System A cannot be estimated with the help of linear structural modeling.

\subsubsection{System B}

In the analysis of system B on sample 1, a well interpretable solution with five correlated factors emerged with eigenvalues of 4.51, 3.91, 2.52, 2.52 and 2.30. The factor matrix of the five-factor solution, which accounts for $46 \%$ of the overall variance, is omitted in this conference paper, since the loadings are shown in 
the linear structural equation models (cf section 5). Pattern matrices can be obtained from the authors.

The analysis of factor intercorrelations reveals a medium correlation of .35 between the first and the second factor. All other correlations are smaller with absolute values of .23 or below.

Factor I represents the quality of system B. It includes items from the field of usability ('Keywording', 'Glanceability' and 'Retrievability') and data quality ('Specificity' and 'Content meets requirements'). It also includes the item 'Process orientation' which could be assigned to both of these domains.

Factor II represents the acceptance of system B. It includes the 'Frequency of usage', 'General evaluation and 'Relevance of system B' items. Furthermore, the 'Information overload' item has a negative loading on this factor, indicating that the feeling of information overload correlates negatively with the other three items. The existence of such a specific acceptance factor is the precondition for further structural analyses, because the causal influences on system B's acceptance can now be estimated.

Factor III represents organizational barriers. It consists of the 'Legal barriers', 'Lack of time and resources for KM', 'Reward for KM', 'Adequate knowledge about KM' and 'System development beyond personal requirements' items.

Factor $I V$ is the personal attitude towards KM, because 'Belief in the general relevance of KM' and, with a negative algebraic sign, 'Fear of judgment' load highly on this factor.

Factor $V$ is labeled negative experiences with system B. It includes the 'Experience of technical flaws' and 'Bad experiences' items.

In summary, five more general aspects were identified that underlie the items with reference to system B and to organizational culture: Quality of the system, acceptance of the system, organizational barriers, personal attitude towards $K M$, and negative experiences with system $B$. The relations between these factors that underlie the usage of this knowledge management system can now be analyzed with linear structural models.

\subsection{Linear Structural Models}

For an analysis of the acceptance of system B, the factors identified above are inserted into a linear structural model. Linear structural models allow - among other possibilities - testing of hypotheses about causal influence between latent (not directly observable) variables. Since factors, as identified in the previous section, are latent variables (constructs that influence groups of items), hypotheses about their influence on each other can now be tested. The general hypothesis is that system acceptance is causally influenced by the other four factors system quality, organ- 
izational barriers, negative experiences with system $B$ and personal attitude towards KM. In figures of linear structural models, factors are displayed as circles. The items that are influenced by these factors are displayed as boxes. Causal influences are displayed as pointed arrows with path coefficients (between -1 and 1) that indicate the strength of the causal relation. Correlations are displayed as bidirectional arrows. By quantifying the influence of the factors on the items, the model may confirm the factor analysis from the previous section. It should be noted that linear structural modeling can only reject hypotheses but cannot prove a model since other models might explain the data, too. The completed model for sample 1 with all standard errors (numbers next to boxes), path coefficients and correlations is depicted in figure 1.

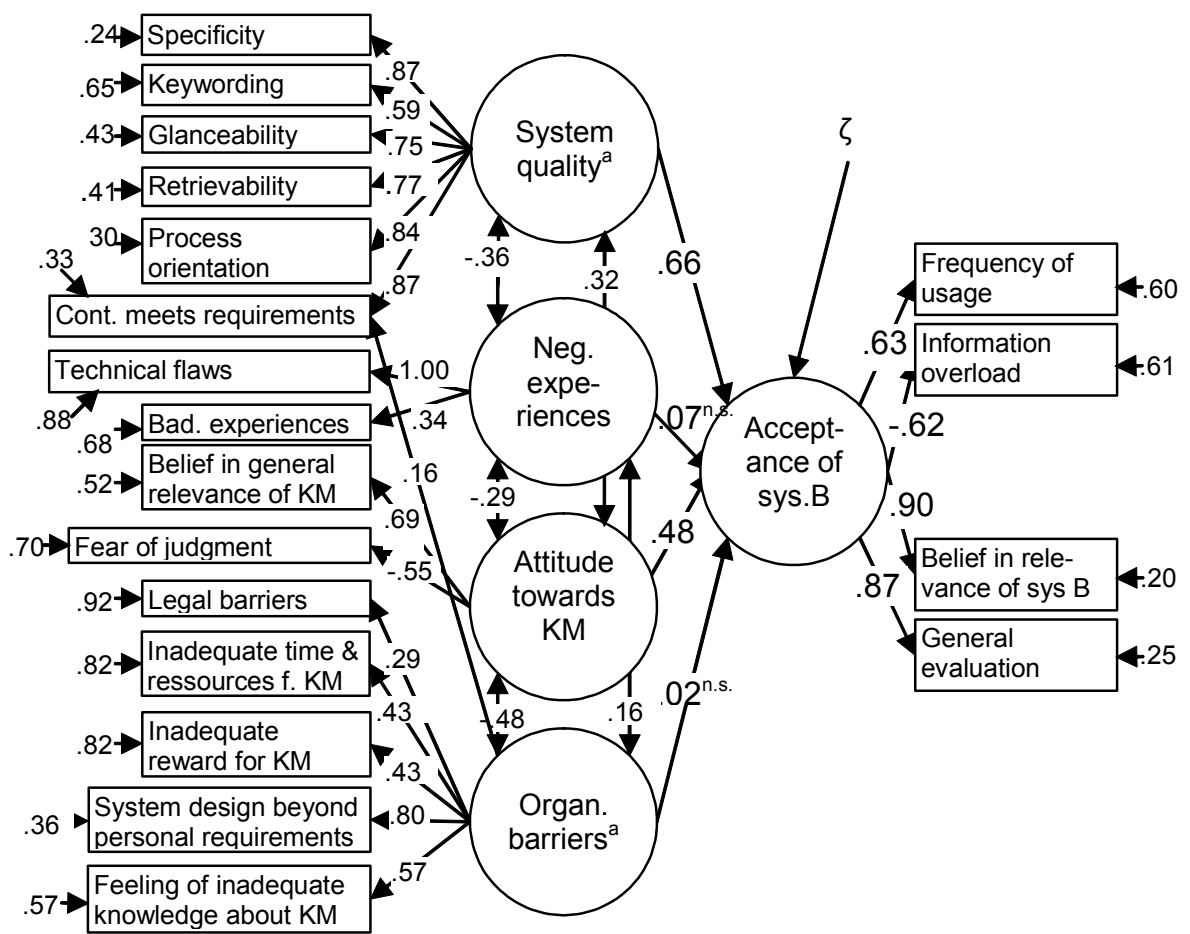

Note. Correlations between measurement errors are omitted. Coefficients marked 'ns' do not have a significant t-value. All other coefficients are significant on the 5\% level.

${ }^{a}$ System quality and organizational barriers correlate with $\mathrm{r}=-.48$.

Figure 1: Linear structural model for the acceptance of system $B$ for sample $1(\mathrm{~N}=307)$.

Except for the path coefficients between negative experiences and acceptance and between organizational culture and acceptance, all path coefficients have a significant t-value at a level of significance of $5 \%$. Goodness of fit statistics shows a chi square value of 82.63 with 94 degrees of freedom, leading to a p-value of 
$0.77^{4}$. Other indices equally support the impression of a excellent model fit: a Root Mean Square Error of Approximation (RMSEA) of 0.000, a Goodness-of-Fit Index (GFI) of 0.99 and an Adjusted Goodness-of-Fit Index (AGFI) of 0.99.

The hypothesis that acceptance is influenced by at least three factors (circles) is not disproved: System quality influences the acceptance of system B to the strongest extent (.66). The second strongest influence on the acceptance is the employees' attitude towards knowledge management (.48). Negative experiences with the system and organizational barriers do not have a direct significant influence on the systems' acceptance. However, there is a substantial negative correlation (-.48) between organizational barriers and the attitude towards knowledge management, indicating an indirect influence of organizational barriers on the acceptance of knowledge management via this attitude.

The excellent fit indices of this model may be inflated since the model was developed on the basis of the same sample that produced the factors. The test of the model on sample 2, which remained unused so far, will prove to be more illuminating.

The model for sample 2 gives a chi-square value of 137.95 with 94 degrees of freedom, leading to a p-value of 0.002 . This comparatively poor value is contrasted by a sufficient RMSEA value below 0.05 (0.04), and very good GFI- and AGFI-values ( 0.99 and 0.97 , respectively). The Q-plot of standardized residuals of the second model is still close to the main diagonal of standardized residuals and very close to the plot of the previous model, which also indicates a good model fit [Balt94]. In summary, the indices do not speak for a rejection of the second model, although they are not as good as the fit of the first model.

The only relevant difference between the coefficients in the second and in the first model is a significant weak negative path coefficient (-.19) between organizational barriers and the acceptance of system B in the second model. Since all other indices differ only slightly in comparison to the first model and do not alter its general strength nor its interpretation, it is not separately displayed. The negative correlation between organizational barriers and attitude towards KM is also present (-.46) and almost as large as in the first model. This is a further indicator for the influence of organizational factors on the acceptance of system B. However, the system quality is still the dominant influence (.67) on the systems' acceptance, followed by the employees' attitude towards knowledge management. The implications of the model are discussed in the following section.

4 Note that in linear structural models, the model hypothesis is that the empirical parameter matrix and the model matrix are not different, thus the p-value has to be as high as possible and not below 0.05 . 


\section{Discussion}

The results from the comparison of means show clearly that system B is much more accepted and more frequently used than system $\mathrm{A}$. The differences in ratings are not only highly significant, but also - with effect sizes above one standard deviation - very large. System A's lack of 'glanceability', process orientation, retrievability and specificity of included content along with poor keywording, led to a generalized negative view of the system. Factor analysis for system B indicated a more differentiated perception of the system which enabled the analysis of the influence on its acceptance with structural modeling. The linear structural analysis of system B shows that three factors determine its acceptance: Its quality (with reference to usability and content), the general attitude of the employees towards $\mathrm{KM}$, and organizational barriers. In the following section, these findings are discussed further, applying them to the four paradigmatic views outlined in section 2 .

\subsection{Comparison of the Findings to the Organizational Barriers' Perspective}

As discussed in section 2, some authors claim that organizational barriers are responsible for shortcomings in knowledge management systems. These thinkers are supported by the employees' assessment of system A in this study. Employees here stated that they are inadequately rewarded for their initiatives in KM and by the fact that they report insufficient time and resources for KM activities.

The linear structural models for system B provide a more differentiated picture. Given the negative experiences with system A, which was introduced prior to system $\mathrm{B}$, it is not surprising that system quality influences acceptance most strongly. Surprisingly, the 'Negative experiences' factor does not appear to influence the system's acceptance significantly. However, there is a significant correlation (.29) between negative experiences and the 'personal attitude towards KM' factor, which influences the acceptance of system B to the second strongest extent. This 'Personal attitude towards KM' factor also has a seizable correlation ( -.47 , averaged over both models) with organizational barriers, which shows a significant direct influence on acceptance only in the second structural model. This correlation cannot tell which factor influences which, but it appears to be more plausible that the perception of existing organizational barriers influence the personal attitude towards KM more than the other way round.

The inclusion of the 'Time and resources for KM' and 'Inadequate reward for KM' items in the organizational barriers factor also supports the first group. The contradiction between this group and those thinkers who blame extrinsic motivation in KM for its failure can be solved by taking a middle position: employees should be primarily intrinsically motivated to make use of a KM-system, and should then be rewarded extrinsically in return for their efforts [FrOs02]. This im- 
plies that employees do not require rewards every single time they actually use or feed the system. The latter leads to camouflage behavior [Snow02], but the complete neglect of motivation and acknowledgement for expected behavior will also preclude desired outcomes.

\subsection{Comparison of the Findings to the Codification versus Personalization Perspective}

Authors from the second group, who blame the absence of a flanking personalization approach next to codification efforts, could be supported by the observation that the organization undertook no endeavors in the field of organized personalization methodologies like supporting, for instance, communities of practice. This is currently being discussed inside the organization, as a strategy paper indicates. However, the slight rejection of the 'Superiority of unofficial information channels' item, the lack of interest in communication tools (which were removed from system B due to a lack of usage) and the demand for structured, formal and specific information do not provide strong empirical support for this view.

\subsection{Comparison of the Findings to the Ill-Conceived Understanding of Knowledge Perspective}

The fact that system A was designed as a "knowledge repository" (quote from the system handbook) supports critiques from the third view that questions the suitability of knowledge storage. Furthermore, the obvious lack of socio-technical system design, derived from the fact that end user requirements were not properly taken into account, also supports this group.

The importance of the idea that proper knowledge should be context specific can be seen in the success of system B in comparison with system A: system B was designed within the context of a specific local department. Its navigation, its contents, its interface and its language are specific to a subgroup of the organization whose members share a working context. System A did include a filtering mechanism that was intended to provide relevant context as well, but this pre-defined mechanism based on a theoretical taxonomy only affected the selection of content, whereas all other aspects of the system were identical worldwide.

\subsection{Comparison of the Findings to the KM Sceptics' Perspective}

The fourth group's view that at least implicit knowledge is not manageable, may be supported by the fact that system B apparently doesn't attempt to manage implicit or tacit knowledge. System features like discussion forums and the CV 
search facility - which could be seen as a way of opening access to others' implicit knowledge - were removed from system B because they were not used. Of course, system B is in an early stage of development; so, it is not precluded that ITsystems could be able to support access to implicit knowledge. But the more radical assumption that KM is entirely useless is contradicted by the high acceptance and frequent usage of system B. The item 'All in all, I consider KM to be an important thing in which our company should show commitment.' received the highest agreement ( 4.5 on average where 5 is "totally agree") in the entire questionnaire. The good acceptance of system B also refutes this position.

\subsection{Integration of the Findings towards a Conceptual Framework}

None of the existing views can claim to explain all possible shortcomings sufficiently. The fact that shortcomings from two domains, organizational barriers and the concept of knowledge, were clearly identified and that shortcomings from the second domain, codification versus personalization, proved fruitful for the discussion demonstrates the importance of a broader conceptual framework - a framework that incorporates the pitfalls for the establishment of any knowledge management system.

The first aspect to consider is the quality of the system with regard to its design and its content. In this particular case, it is evident that the quality of an IT system had a strong influence on its acceptance. Generally speaking, this means that a poorly designed system will not be used and will eventually be abandoned and viewed as irrelevant with the risk of discrediting knowledge management in general. Systems will be perceived as good if they contain specific information with good meta tags that make it easy to find and retrieve it, and if they are geared to the needs of the employees and their daily work processes. This requires detailed knowledge of the employees' requirements when designing KM systems, which can hardly be achieved without intensive user involvement. The common notion of IT systems as "hygiene factors" [Snow02], i.e. an engineering task for ITspecialists, or " $\mathrm{x} \%$ technology and y \% culture" [Snow00, p. 240] creates the impression that KM systems are somewhat simple and almost natural: that the actual challenges come after the implementation of these systems. This study underlines the complexity and difficulty of the design of good and usable systems. The required processes start well before systems are introduced, and make the early inclusion of employees during strategic development essential.

Thus, and this is the second aspect of any useful framework, the users and their needs have to be the focus of KM, especially in the early stages of development and implementation. Development without proper consideration of end users' requirements will lead to a failing system, as seen with system A. The social and human aspects of KMS are most probably more important than the technical as- 
pects [Sch $\left.{ }^{+} 04\right]$. The disregard of socio-technical system design, as formulated by thinkers from the third paradigmatic view, is a barrier which is clearly visible in this case.

This focus on people also includes care for the personal attitudes of employees towards knowledge management. This can be addressed by preventing that the members of the organization develop a fear of being judged when they share their knowledge. The personal attitudes can also be targeted by supporting the belief in the general relevance of knowledge management. This could include vivid communication on what the organization is trying to achieve with knowledge management as well as the active system use by higher management persons becoming models for all others.

The third aspect for a realistic KMS framework is attention to organizational barriers. This includes the targeting issues that have been mentioned in literature [Nort99] such as adequate time and training for system use, prevention of legal barriers, and motivation for knowledge management. Organizational aspects also include giving appropriate information on this management strategy, and eliciting appreciation for and insight in the intricacies of usable, needed knowledge in quality circles.

Finally, the system design should balance all three piles of any KMS framework: IT-system, people, and organization [ReMa00]. However, in this study and probably in most other cases, the central element are people and their requirements towards which the other factors should be oriented. This is supported by the findings of the delphi study on the future of knowledge management [ $\left.\mathrm{Sch}^{+} 04\right]$, which also indicate that successful knowledge management is one that has a primary focuse on human aspects. The focus on people implies that a gradual, piecemeal development strategy is much better able to satisfy the most urgent knowledge needs of employees, and thus is more likely to be successful and to guide further developments as is evident from the much more successful system B. It is interesting that already long ago the philosopher Karl Popper recommended such an approach with the decisive argument that human knowledge is always imperfect; thus, a holistic plan, even from the most experienced specialists, is always likely to fail [Popp61]. Learning is a gradual process, for individuals and even more for organizations, and this holds perhaps in no area more true than in the area of knowledge management.

\section{Conclusion}

The integration of the four paradigmatic views about likely obstacles to successful knowledge management into a single multi-dimensional framework appears necessary and possible, as references to three out of four paradigmatic views were 
identified in this study. Such a framework would include the three piles of ITsystem, people and organization, with a prime focus on people. Further theoretical and empirical efforts appear necessary for the concretion and testing of such a framework. For example, a theoretical and empirical refinement of the developed questionnaire could even more precisely point to possible shortcomings of system design and organizational barriers prior to their occurrence. The prospects of such a framework are promising. The very existence of four divergent paradigmatic views of shortcomings in KM systems and the identification of their usefulness in evaluating KM systems in practice show convincingly that much can be gained in the field of knowledge management by an integrative framework.

\section{References}

[Ambr00] Ambrosio, J.: Knowledge management mistakes. Online Journal Article. http://www.computerworld.com/industrytopics/energy/story/0,10801,46693,00.html, 2000, Accessed 2000-08.03.

[Amel02] Amelingmeyer, J: Wissensmanagement. Analyse und Gestaltung der Wissensbasis von Unternehmen. Dt. Univ.-Verl.: Wiesbaden, 2002.

[Balt94] Baltes-Götz, B.: Einführung in die Analyse von Strukturgleichungsmodellen mit LISREL 7 und PRELIS unter SPSS. Online Script. http://www.uni-trier.de/urt/user/ baltes/docs/lisrel/lisrel7.pdf, 1994, Accessed 2003-08.10.

[DaPr98] Davenport, T. H.; Prusak, L.: Working knowledge: how organizations manage what they know. Harvard Business School Press: Cambridge, MA, 1998.

[Druc93] Drucker, P.: Post-capitalist society. Econ: New York, 1993.

[Euro00] European Council: Lisbon European Council 23 and 24 March 2000: presidency conclusions. http://www.europarl.eu.int/summits/lis1_en.htm, 2000, Accessed 2003-0924.

[FaPr98] Fahley, L.; Prusak, L.: The eleven deadliest sins of knowledge management. California Management Review 40, 1998: pp. 265-276.

[Flan54] Flanagan, J. C.: The critical incident technique. Psychological Bulletin 51, 1954: pp. 327-359.

[Foun99] Fountain, J. E.: A note on the critical incident technique and its utility as a tool of public management research. Paper presented at the Annual meeting of the Association of Public Policy and Management, November 4-6, 1999.

http://www.ksg.harvard.edu/prg/fountain/citechnique.pdf, 1999, Accessed 2004-9-27

[FrOs02] Frey, B. S., \& Osterloh, M. (Eds.): Successful management by motivation. Balancing intrinsic and extrinsic incentives. Springer: Berlin, Heidelberg, New York, 2002.

[GrKa02] Gronau, N.; Kalisch, A.: Knowledge content management system - a framework integrating content management and knowledge management. In: Arabnia, H (Ed.) Pro- 
ceedings of the International Conference on Information and Knowledge Engineering (IKE’02), Las Vegas 2002. IKE publisching: Las Vegas, 2002, pp. 150-153.

[Güld99] Güldenberg, S.: Wissensmanagement und Wissenscontrolling in lernenden Organisationen. Gabler / Dt. Univ. Verl.: Wiesbaden, 1999.

[Han $\left.{ }^{+} 99\right]$ Hansen, M.; Nohira, N.; Tierney, T.: What's your strategy for managing knowledge? Harvard Business Review 77, 1999: pp. 106-116.

[JöSö79] Jöreskog, K. G.; Sörbom, D. (Eds.): Advances in factor analysis and structural equation models. Abt Books: Cambridge, MA, 1979.

[JöSö93] Jöreskog, K. G.; Sörbom, D.: Structural equation modeling with the SIMPLIS command language. Lawrence Erlbaum Associates: Hillsdale, NJ, 1993.

[JöSö03] Jöreskog, K. G.; Sörbom, D.: LISREL 8.54: SSI Central, 2003.

[Labo70] Labovitz, S.: The assignment of numbers to rank order categories. American Sociological Review 35, 1970: pp. 515-524.

[Malh04] Malhotra, Y.: Why Knowledge Management Systems Fail? Enablers and Constraints of Knowledge Management in Human Enterprises. In: Holsapple, C.W. (Ed.) Handbook on Knowledge Management 1: Knowledge Matters. Springer-Verlag: Heidelberg, 2004, pp. 577-599.

[Noac03] Noack, H.-C.: Worauf sich Unternehmen in der Zukunft konzentrieren: Welche Managementmethoden haben Vorrang. Frankfurter Allgemeine Zeitung 18, 2004: p.18.

[NoKo98] Nonaka, I.; Konno, N.: The concept of "ba": building a foundation for knowledge creation. California Management Review 40 (3), 1998: pp. 40-54.

[NoTa95] Nonaka, I.; Takeuchi, H.: The knowledge-creating company. Oxford University Press: New York, 1995.

[Nort99] North, K.: Wissensorientierte Unternehmensführung (2. Aufl.). Gabler: Wiesbaden, 1999 .

[Pola66] Polanyi, M.: The tacit dimension. Doubleday: Garden City, NY, 1966.

[Popp61] Popper, K. R.: The poverty of historicism. 2nd ed., Routledge: London, 1961.

[ReMa00] Reinmann-Rothmeier, G.; Mandl, H.: Ein pädagogisch-psychoplogischer Ansatz zum Wissensmanagement - ein Widerspruch in sich? Forschungsbericht, LudwigsMaximilians-Universität, Institut für Pädagogische Psychologie und Empirische Pädagogik München, 2000.

[Schn01] Schneider, U.: Die 7 Todsünden im Wissensmanagement. Frankfurter Allgemeine Buch: Frankfurt a. M., 2001.

[Sch$\left.{ }^{+} 04\right]$ Scholl, W.; König, C.; Meyer, B.; Heisig, P.: The future of knowledge management: an international delphi study. Journal of Knowledge Management 8 (2), 2004: pp. 19-35.

[Scho04] Scholl, W.: Innovation und Information. Wie in Unternehmen neues Wissen produziert wird. Hogrefe: Göttingen, 2004. 
[ScGe03] Schreyögg, G.; Geiger, D.: Kann die Wissensspirale Grundlage des Wissensmanagements sein? Diskussionsbeiträge des Institut für Managements 20, 2003: pp. 2-31.

[Schü96] Schüppel, J.: Wissensmanagement: Organisatorisches Lernen im Spannungsfeld von Wissens- und Lernbarrieren. Gabler: Wiesbaden, 1996.

[Schü03] Schütt, P.: Die dritte Generation des Wissensmanagements. KM-Journal 1, 2003 : pp. 1-7.

[Snow00] Snowden, D.: The social ecology of knowledge management. In. Despres, C.; Chauval, D. (Eds.) Knowledge Horizons. Butterworth: Boston, 2000, pp. 237-265.

[Snow02] Snowden, D.: Complex acts of knowing - paradox and descriptive selfawareness. Online paper. http://www-1.ibm.com/services/files/complex.pdf, 2002, Accessed 2002-09-07.

[Stac01] Stacy, R.: Complex responsive processes in organizations: learning and knowledge creation. Routledge: London, 2001.

[Steh94] Stehr, N.: Knowledge societies. Sage: London, 1994.

[Svei01] Sveiby, K.-E: What is knowledge management? http://www.sveiby.com/ KnowledgeManagement.html, 2001, Accessed 2003-07-04.

[VKro98] Von Krogh, G.: Care in knowledge creation. California Management Review 40, 1998: pp. 133-153. 